\title{
THE CAROTID PULSE I: DIAGNOSIS OF AORTIC STENOSIS BY EXTERNAL RECORDINGS
}

BY

\author{
BRIAN ROBINSON
}

From St. George's Hospital, London S.W.I

Received May 10, 1962

The brachial pulse is unreliable in the diagnosis of aortic stenosis as it may fail to show distinctive changes (Hancock and Abelmann, 1957; Hancock and Fleming, 1963). The carotid pulse should be more satisfactory for this purpose, since it reflects central events more clearly and external recordings reproduce the pressure pulse simply and adequately (Robinson, 1963). In 1956 Duchosal et al. reported the use of external carotid pulse recordings in the diagnosis of aortic stenosis. Daoud, Reppert, and Butterworth (1959) and Smith et al. (1959) also found the method valuable, but these investigators relied on clinical diagnosis in most of their patients, and each group used a different method to analyse the pulse. The present study is an attempt to define reliable diagnostic criteria, and patients with aortic stenosis have been included only when the diagnosis has been proved by left heart catheterization, operation, or necropsy. Their pulse tracings have been compared with those from healthy people and patients with a wide variety of cardiovascular disorders.

\section{Method}

The carotid pulse was recorded by an external method similar to that of Duchosal et al. (1956). With the patient reclining at an angle of about $60^{\circ}$, an air-filled rubber cuff $23 \times 4 \mathrm{~cm}$. was placed around the neck and held in position by a leather band (Fig. 1). The pressure in the cuff was raised by $2-3 \mathrm{~mm}$. $\mathrm{Hg}$, the system connected to an airfilled transducer (Cambridge diaphragm 73422, and transducer 73428), and the tracing photographically recorded at a paper speed of $100 \mathrm{~mm}$. $/ \mathrm{sec}$. The frequency response of the transducer and recording system was flat to $60 \mathrm{c} / \mathrm{s}$.

Thirty-three patients with aortic stenosis were investigated and their ages ranged from 11 to 65 years: the diagnosis was confirmed by left heart catheterization in 26 , open operation in 14 , and necropsy in four. The stenosis was valvular in 29 patients of whom 13 had significant aortic regurgitation (severe and dominant in 5) and 8 had mitral valve disease. Subvalvular stenosis was present in 4 patients, 1 of whom also had a large patent ductus arteriosus. Carotid pulse tracings were also obtained in 75 healthy children and young adults, and 164 patients with a wide variety of cardiovascular disorders other than aortic stenosis, including congenital, rheumatic, ischæmic, and hypertensive heart disease.

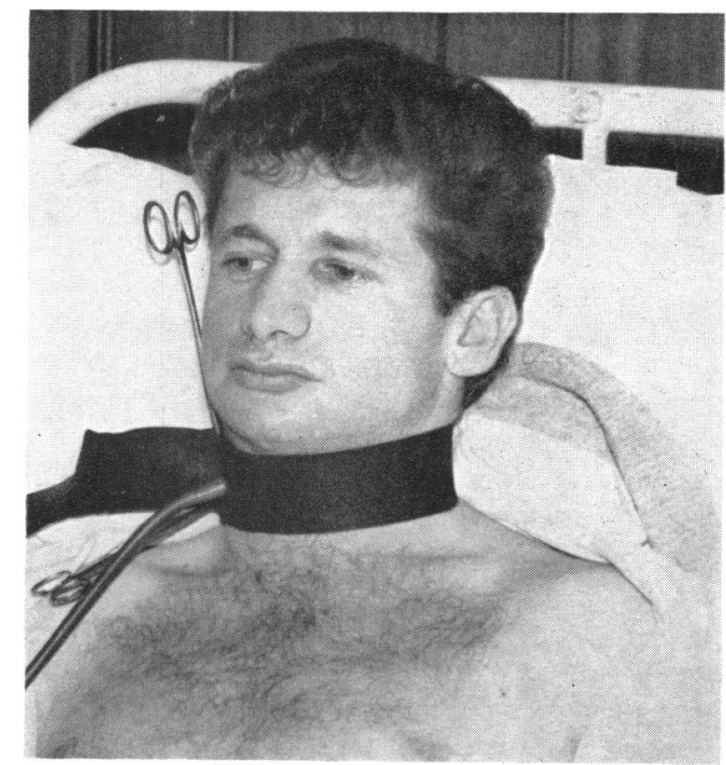

FIG. 1.-Neck cuff for external recording of the carotid pulse. A leather band holds the air-filled rubber cuff in position and provides a rigid backing that increases
the sensitivity. 51 
Terminology. The normal carotid pulse commonly shows two major inflections during systole ( Fig. 2, B and $\mathrm{C}$ ), either of which may give rise to the summit, the other forming a shoulder. These inflections are also seen in the aortic and brachial pulses, and have received a variety of names. In this paper the peak or

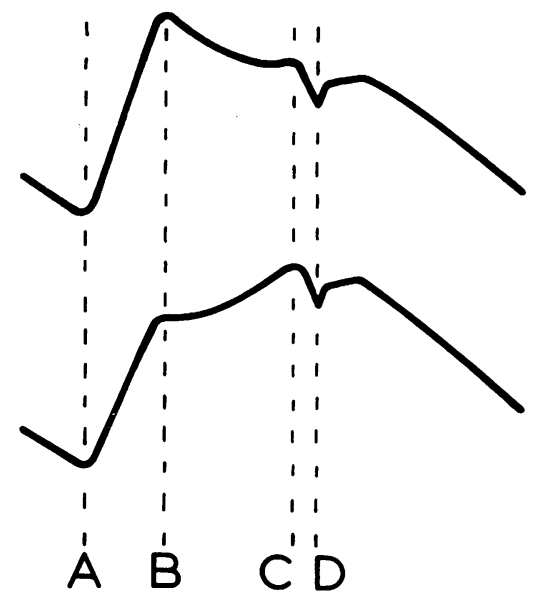

FIG. 2.-The structure of the normal carotid pulse. $A$ is the origin, $B$ the first inflection, $\mathbf{C}$ the second inflection, and $\mathrm{D}$ the incisura. Note that the summit may be formed by either the first or second inflection. shoulder about $0 \cdot 10-0 \cdot 12 \mathrm{sec}$. after the onset, otherwise known as the precussion wave or anacrotic shoulder, is called the first inflection. The peak or shoulder about $0 \cdot 20-0 \cdot 24 \mathrm{sec}$. after the onset, otherwise known as the tidal wave or end systolic shoulder, is called the second inflection. The bend on the upstroke earlier than the normal first inflection which is often seen in aortic stenosis is called the anacrotic shoulder. The upstroke time is measured from the onset of the pulse wave to the summit (Fig. 2, A-B in the upper tracing, A-C in the lower). The ejection time is measured from the onset of the pulse wave to the incisura (Fig. 2, A-D). When the incisura is not sharp, as often occurs in aortic stenosis, it is taken to be at the point of sudden inflection on the downstroke.

\section{RESULTS}

Normal. The contour of the normal carotid pulse is shown in Fig. 3. There is a rapid initial rise to the first inflection, $0 \cdot 10-0 \cdot 12 \mathrm{sec}$. after the onset. The pulse then rises, falls, or continues as a plateau to the second inflection $0 \cdot 20-0 \cdot 24$ sec. after the onset; and a sharp incisura follows.

The upstroke time varies widely since either the first or second inflection may form the summit. The ejection time, shown plotted against the cycle length in Fig. 4, is less variable than the upstroke time, particularly when allowance is made for the heart rate. The values found agree with those of Weissler, Peeler, and Roehll (1961) at cycle lengths greater than 0.8 sec., but are higher at shorter cycle lengths. This discrepancy might be due to age differences, since Weissler et al. confined their studies to adults whereas most of the values at shorter cycle lengths in this series were obtained in children.

Abnormal (other than aortic stenosis). The contour was often normal in children with congenital heart disease, but in other conditions changes in the form of the pulse were frequent. In the hypertensive and the elderly, the pulse often showed a relatively smooth rise to a summit formed by the second inflection, the first inflection being absent or reduced to a minor bend on the upstroke (Fig. 5A). The first inflection also tended to be inconspicuous in uncomplicated mitral stenosis (Fig. 5B), but occasionally it was represented by a notch on the upstroke (anacrotic notch): this was more common when mitral regurgitation was present as well (Fig. 5C). Aortic regurgitation when mild caused little change in the pulse contour, but when it was severe an unusually rapid upstroke was sometimes seen (Fig. 5D). When the summit was clearly defined and all suggestion of a systolic plateau was absent (Fig. 5, A, B, and C), the upstroke time never exceeded $0.26 \mathrm{sec}$. at any heart rate (Fig. 7).

The ejection time (Fig. 9) was within the normal range in most patients, but in a few with lesions such as mitral regurgitation and severe heart failure, it was unduly short, probably due to diminished stroke output. Prolongation beyond the normal range occurred only once in the absence of a gradient across the aortic valve. This was in a patient with gross, pure aortic regurgitation, seen after the series was completed, who had an ejection time of $0.38 \mathrm{sec}$. at a cycle length of $1.09 \mathrm{sec}$.

The inconstancy and relatively minor nature of many of these pulse changes renders them of little positive value in diagnosis: nevertheless, their recognition is important as some of them resemble, and might be confused with, the changes occurring in aortic stenosis.

Aortic Stenosis. All 29 patients with valve stenosis and three of the four with subvalvular 

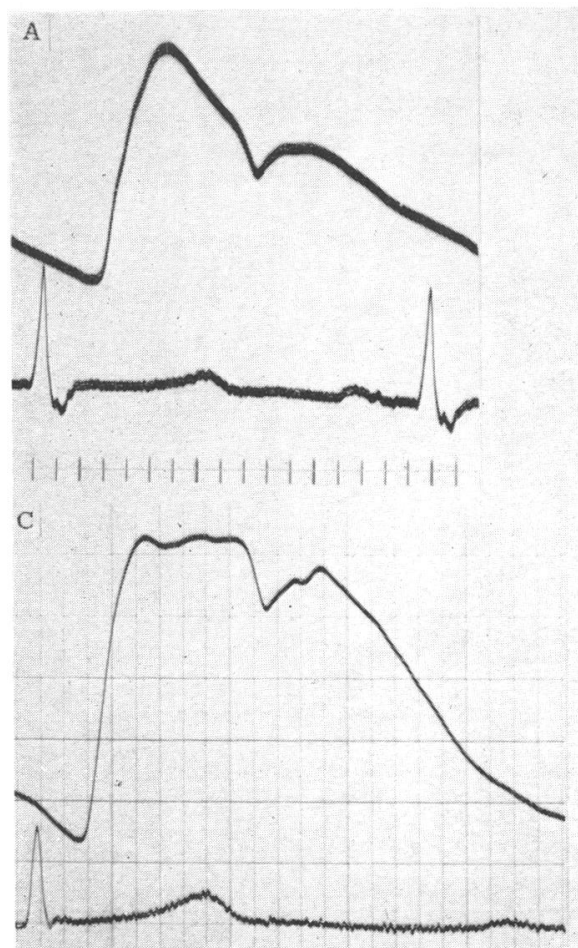

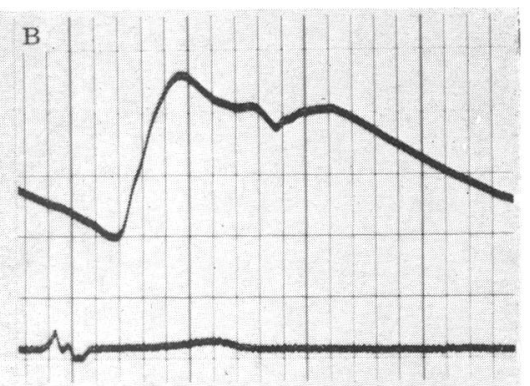

D

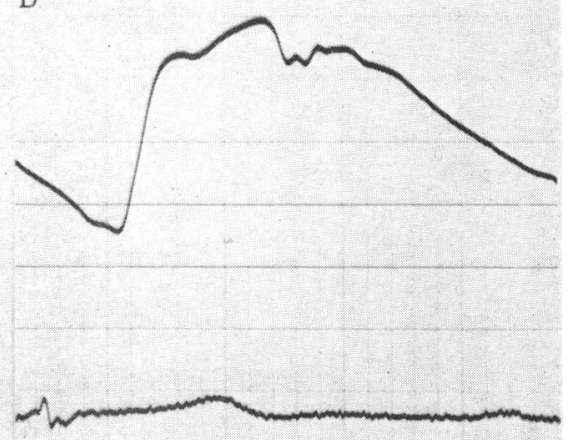

FIG. 3.-External carotid pulse tracings from normal subjects. Time intervals are 0.04 and $0 \cdot 2 \mathrm{sec}$. and are the same in all the illustrations. The height of the tracings is arbitrary and no attempt has been made to keep the amplification constant. The normal carotid pulse always shows a rapid rise to the first inflection, but this may be followed by a fall (A and B), a plateau (C), or a slow rise (D), which leads to the second inflection. The incisura is sharp.

TABLE I

Abnormalities of External Carotid Pulse in Various Types of Aortic Stenosis

\begin{tabular}{|c|c|c|c|c|c|}
\hline Diagnosis & Number & $\begin{array}{l}\text { Contour abnormal } \\
\text { (with systolic } \\
\text { vibrations except } \\
\text { where noted) }\end{array}$ & $\begin{array}{l}\text { Upstroke time } \\
\text { prolonged }\end{array}$ & $\begin{array}{l}\text { Ejection time } \\
\text { prolonged }\end{array}$ & $\begin{array}{c}\text { Pulse abnormal } \\
\text { on at least } \\
\text { one test }\end{array}$ \\
\hline $\left.\begin{array}{l}\text { A.S.-severe } \\
\text { A.R.-slight or absent }\end{array}\right\}$ & 8 & $\begin{array}{c}6 \\
\text { (vibrations absent } \\
\text { in 2) }\end{array}$ & 5 & 4 & 8 \\
\hline \multirow{2}{*}{$\begin{array}{l}\text { A.S.-mild to moderate } \\
\text { A.R.-all grades } \\
\text { A.S.-all grades with M.S. } \\
\text { Subvalvular aortic stenosis }\end{array}$} & 12 & 11 & 7 & 10 & 12 \\
\hline & $\begin{array}{l}9 \\
4\end{array}$ & $\begin{array}{l}8 \\
3\end{array}$ & $\begin{array}{l}4 \\
2\end{array}$ & $\begin{array}{l}5 \\
3\end{array}$ & $\begin{array}{l}9 \\
3\end{array}$ \\
\hline Total & 33 & 28 & 18 & 22 & 32 \\
\hline
\end{tabular}

A.S. = aortic stenosis

A.R. = aortic regurgitation

M.S. = mitral stenosis 


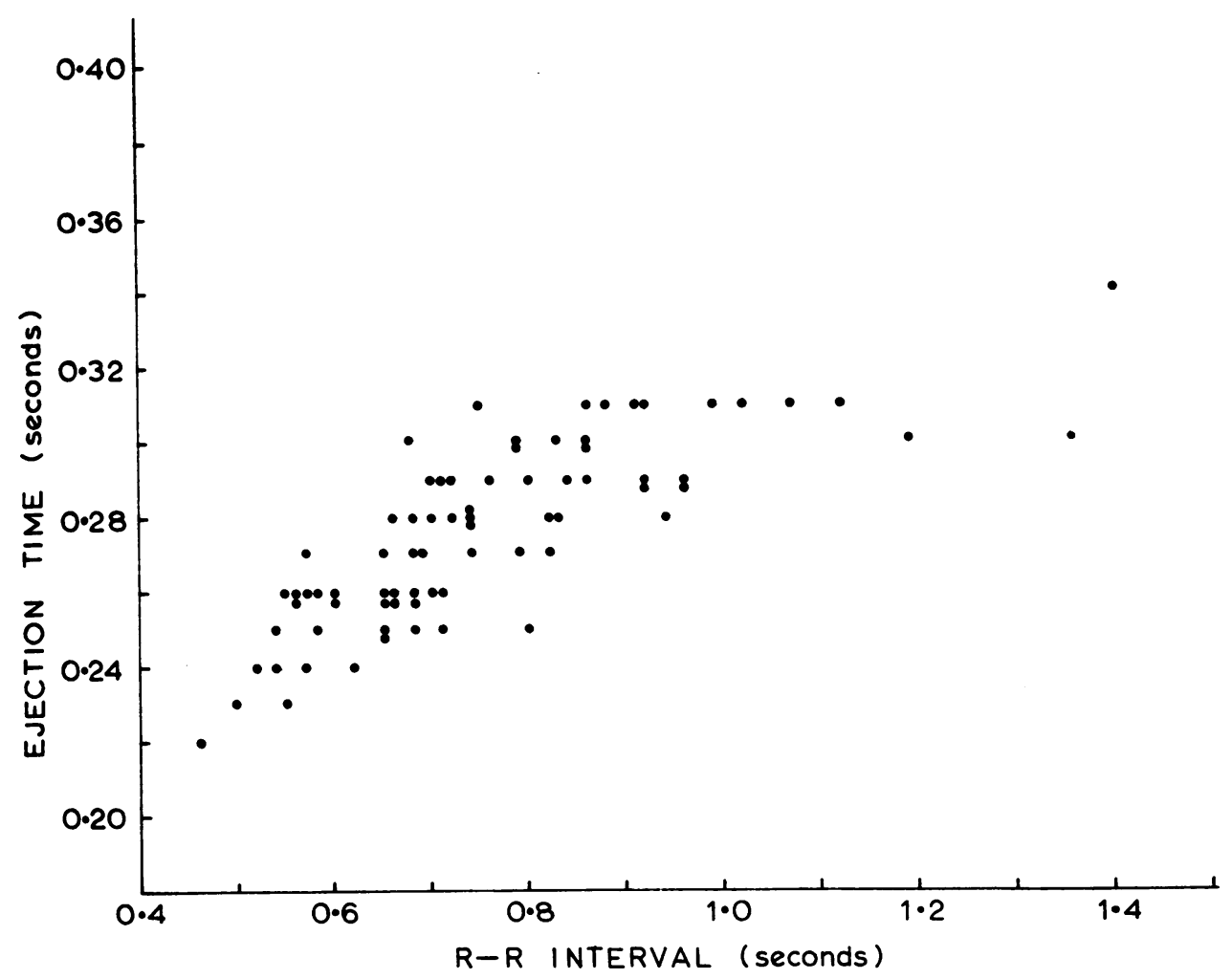

Fig. 4.-Ejection time of the external carotid pulse in 75 normal children and young adults plotted against the length of the preceding cycle measured from the electrocardiogram. The upper and lower limits of ejection time vary with the heart rate.

stenosis showed diagnostic changes in the pulse which are summarized in Table I. Several types of pulse contour were seen in valve stenosis. In the most common variety, seen in 17 patients, the initial rise was rapid and of varying height, ending at an anacrotic shoulder from which the pulse rose slowly with superimposed coarse vibrations to the summit in late systole: the incisura was usually poorly marked (Fig. 6, A and B). In three patients this pattern showed minor modifications, the initial upstroke reaching almost the full height of the pulse or systolic vibrations being absent. In another type of pulse, seen in eight patients, the initial rise was not rapid and the upstroke, which in five cases showed vibrations, rose slowly to the summit, either in a straight line or with a bend or shoulder half way up (Fig. 6, C and D): two tracings of this type closely resembled the hypertensive form of pulse. One patient who had severe mitral and aortic stenosis had an atypical pulse with a slow initial rise but a relatively early summit $(0 \cdot 17 \mathrm{sec}$.).

Of the four patients with subvalvular stenosis, one with muscular obstruction, proved at operation, had a pulse contour within normal limits (Fig. 8C). The three with abnormal pulses all showed a rapid initial rise; this was smaller in one (Fig. 8D) and followed by a slower rise to a relatively early summit $(0 \cdot 16 \mathrm{sec}$.): in the other two it was larger, and in one who had a subvalvular membrane (Fig. 8A) the pulse was indistinguishable from the anacrotic type common in valve stenosis.

The upstroke time was greater than $0.26 \mathrm{sec}$. (the upper limit in patients without aortic stenosis) in 18 of the 29 patients with valve stenosis and two of the four with subvalvular stenosis (Fig. 7).

The ejection time (Fig. 9) was in every case at or beyond the upper limit for the heart rate in the 

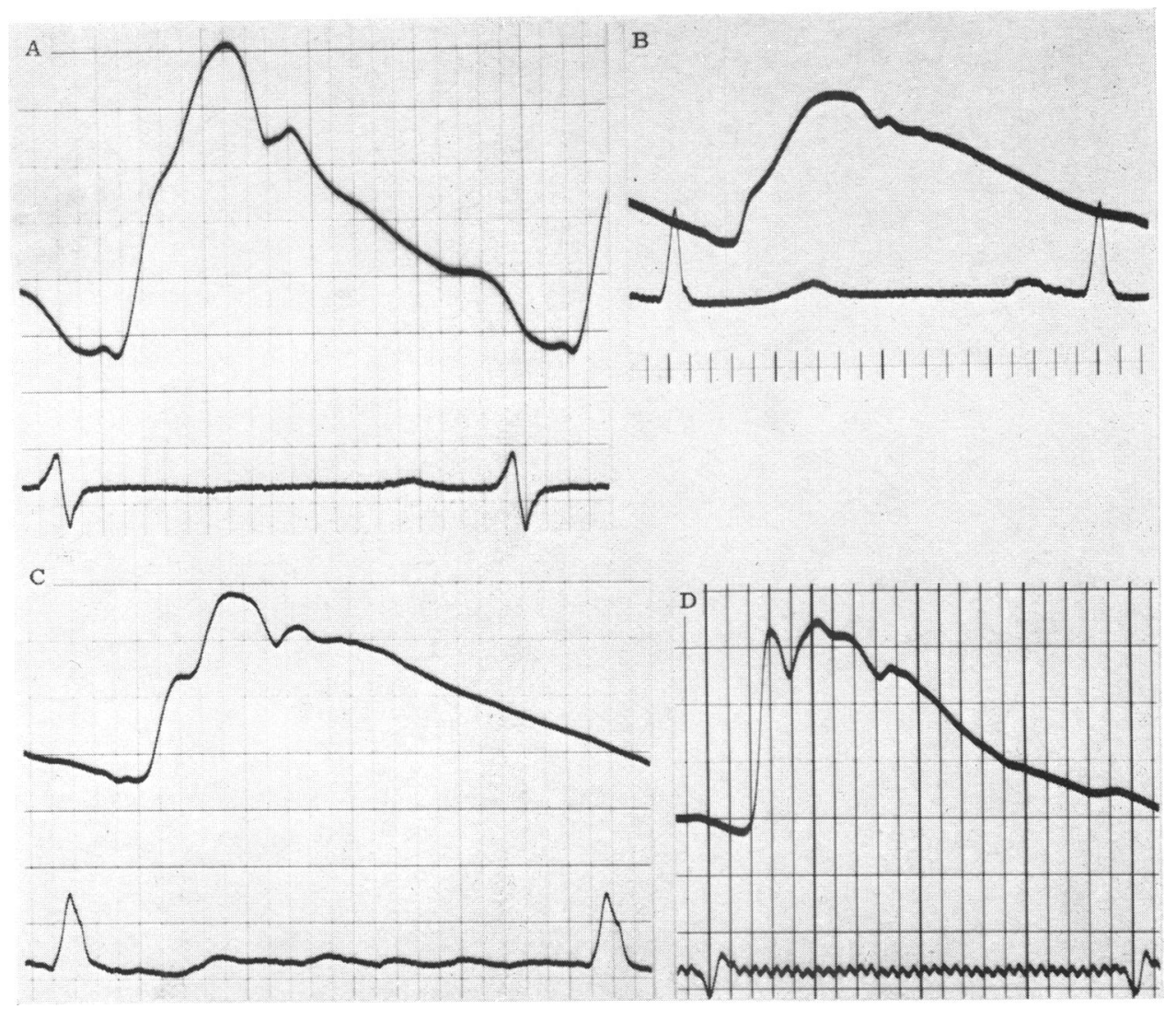

FIG. 5.-External carotid pulse tracings in cardiovascular diseases other than aortic stenosis. (A) hypertension; (B) mitral stenosis; (C) mitral stenosis and regurgitation; (D) pure aortic regurgitation. The pulses vary widely and some show changes that might be confused with those of aortic stenosis. (Further comment in text.)

239 subjects without aortic stenosis: it was unequivocally prolonged in 19 of the 29 patients with valve stenosis and three of the four with subvalvular stenosis.

Assessment of Lesion. In only one of the four patients did the pulse tracing enable subvalvular to be distinguished from valvular stenosis. This was in a man who, in spite of clear evidence of aortic stenosis, had a pulse with a normal rapid rise and a contour incompatible with valvular obstruction (Fig. 8C): at operation muscular obstruction of the outflow tract was found.

Two features in the pulse were of help in assessing the severity of stenosis and associated regurgitation - the rapid initial rise and systolic vibrations. As is shown in Table II, a rapid initial rise half the height of the pulse or more was never seen in adults who had severe aortic stenosis and its presence implied that the obstruction was no more than moderate. A large rapid initial rise was, however, seen in one child with severe stenosis, and this feature cannot be taken to mean that obstruction is not severe when it occurs in children. Absence of a rapid initial rise favoured severe stenosis as did absence of systolic vibrations: the four patients in whom both rapid rise and vibrations were absent all had severe stenosis with little or no regurgitation. Some patients with combined aortic stenosis and regurgitation had a distinctive pulse with a large rapid initial rise ending at a well-marked anacrotic shoulder (Fig. 6B).

Criteria for Diagnosis of Aortic Stenosis. The following criteria have proved useful in analysing the pulse tracing. Obstruction at or near the aortic valve is present if (a) the pulse takes one of the 

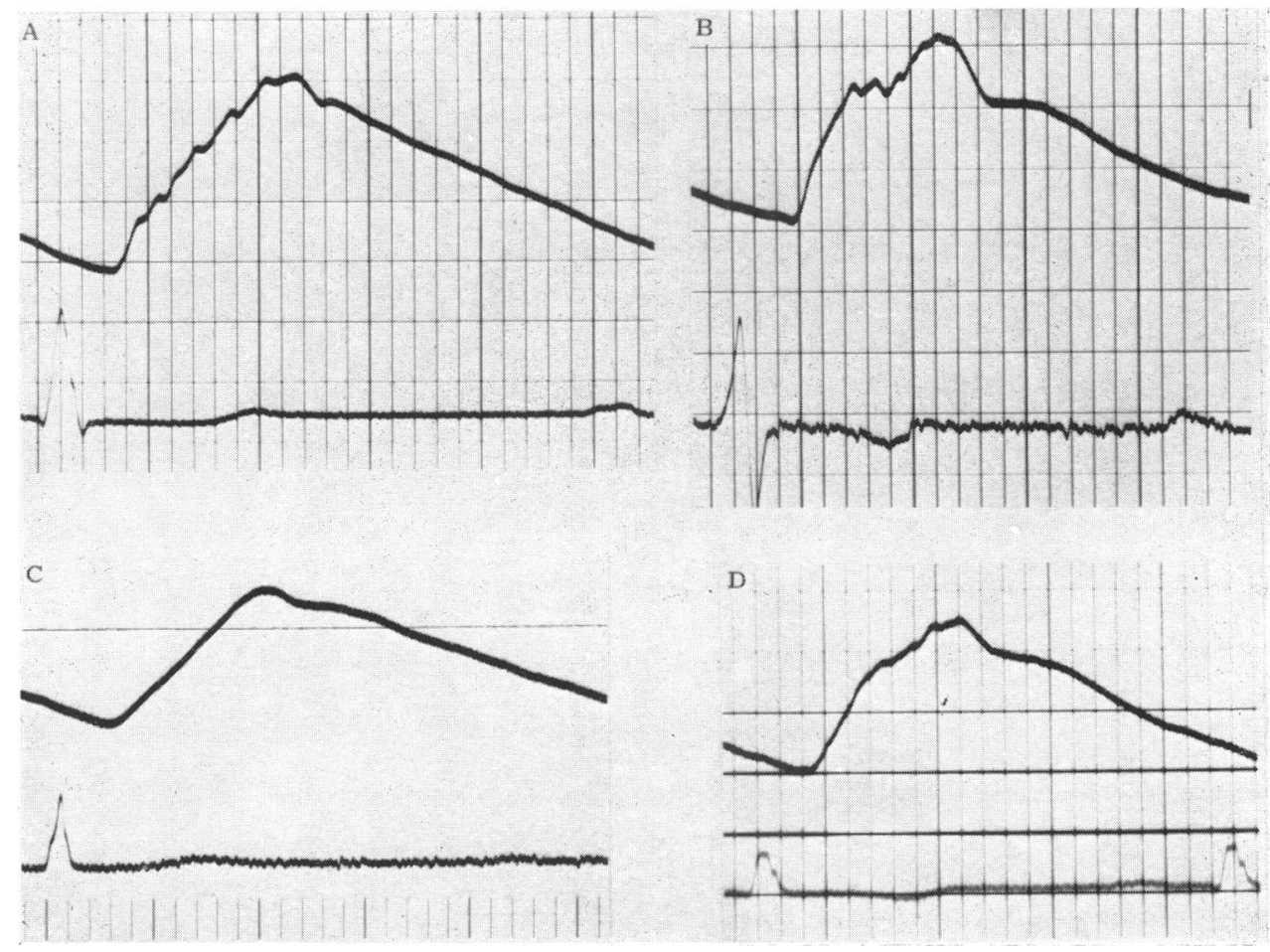

FIG. 6.-External carotid pulse tracings in aortic stenosis. A, mild stenosis and mild regurgitation; $B$, mild stenosis and moderate regurgitation; $C$ and $D$, severe pure stenosis. $A$ and $B$ show the typical pulse of mild to moderate aortic stenosis: an initial rapid rise leads to an anacrotic shoulder from which the pulse rises, with superimposed vibrations, to a late summit. C and D show the typical pulse of severe aortic stenosis: there is no initial rapid rise, vibrations may be absent, and the upstroke is either straight or has a shoulder half way up.

TABLE II

Relation of External Carotid Pulse Contour to Severity of Obstruction in Aortic Stenosis

\begin{tabular}{|c|c|c|c|}
\hline & $\begin{array}{c}\text { Stenosis severe: } \\
\text { regurgitation } \\
\text { insignificant or } \\
\text { absent }\end{array}$ & $\begin{array}{l}\text { Stenosis slight } \\
\text { to moderate: } \\
\text { regurgitation } \\
\text { slight to severe }\end{array}$ & $\begin{array}{l}\text { Stenosis slight: } \\
\text { regurgitation } \\
\text { dominant }\end{array}$ \\
\hline $\begin{array}{l}\text { No rapid upstroke } \\
\text { Rapid upstroke less than half height of pulse } \\
\text { Rapid upstroke half or more of height of pulse }\end{array}$ & $\begin{array}{l}6(4) \\
2 \text { (1) } \\
1 \text { (child) }\end{array}$ & $\begin{array}{r}3 \\
10 \\
2\end{array}$ & $\begin{array}{l}0 \\
0 \\
5(1)\end{array}$ \\
\hline
\end{tabular}

Figures in parentheses indicate patients who did not show systolic vibrations.

typical forms (Fig. 6) and shows systolic vibrations, or (b) the pulse contour, although not typical, is compatible with the diagnosis and the upstroke time is geater than $0.26 \mathrm{sec}$., or (c) the pulse contour, although not typical, is compatible with the diagnosis and the ejection time is prolonged for the heart rate.

Obstruction is unlikely to be present in the absence of one of these changes, and is extremely unlikely if the ejection time is at or below the lower limit of normal.

The ejection time is sometimes of great help in excluding aortic stenosis when a basal ejection 


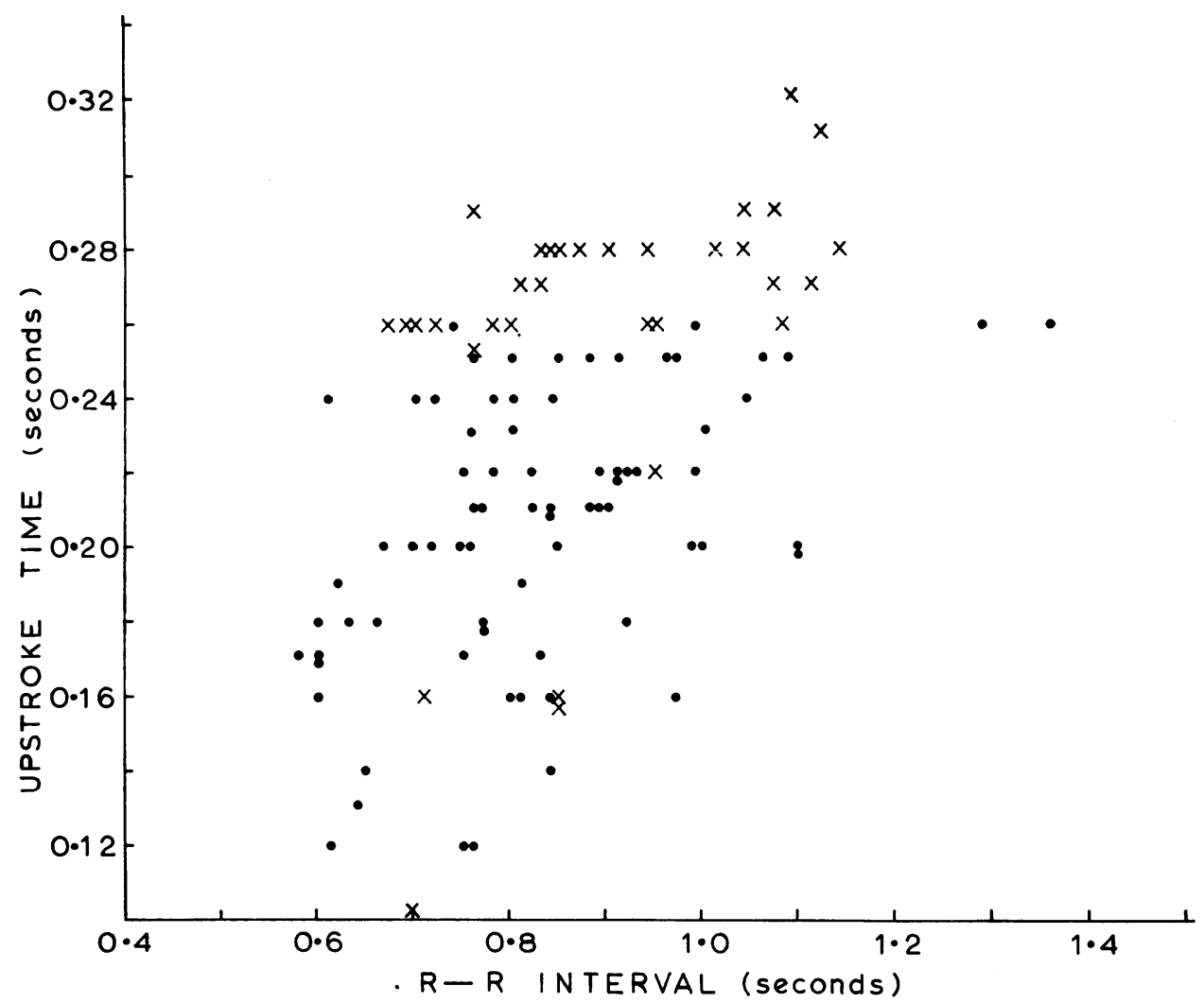

FIG. 7.-Upstroke time of the external carotid pulse in 33 patients with aortic stenosis (crosses) and 74 patients with normal hearts or lesions other than aortic stenosis (dots) plotted against the length of preceding cycle measured from the electrocardiogram. In the absence of aortic stenosis, the upper limit of the upstroke time is $0.26 \mathrm{sec}$. and this applies to any heart rate. When stenosis is present, the upstroke time tends to be prolonged, but there is considerable overlap with the normal range.

murmur is heard in a patient who also has signs of mitral regurgitation. The pulse may be small and difficult to analyse clinically, but the finding of an ejection time at or below the lower limit of normal (as it is likely to be in mitral regurgitation) excludes significant aortic stenosis. In two cases of this sort, submitted to left ventricular puncture before the significance of the short ejection time was appreciated, no gradient was found across the aortic valve.

\section{Discussion}

These results confirm previous reports that external carotid pulse recordings are useful in the diagnosis of aortic stenosis (Duchosal et al., 1956; Daoud et al., 1959; Smith et al., 1959). No single test, however, has been found satisfactory for analysing the pulse. Duchosal et al. (1956) looked for prolongation of the time taken for the upstroke to achieve half the total height of the pulse ("t" time): in the present series, this measurement was sometimes as high as 0.09 sec. without obstruction at the aortic valve, and higher values were observed in only 12 of the 33 patients who had aortic stenosis. The method of Daoud et al. (1959) relies on the steepness of the initial rise and is influenced to some extent by the amplification which was not kept constant in the present series: even so, it seems unlikely that their approach would have revealed the diagnosis in many of the 25 patients whose pulses had a rapid initial rise. The importance of systolic vibrations as an indicator of aortic stenosis (Smith, 1955; Smith et al., 1959) has been confirmed, but they were sometimes 

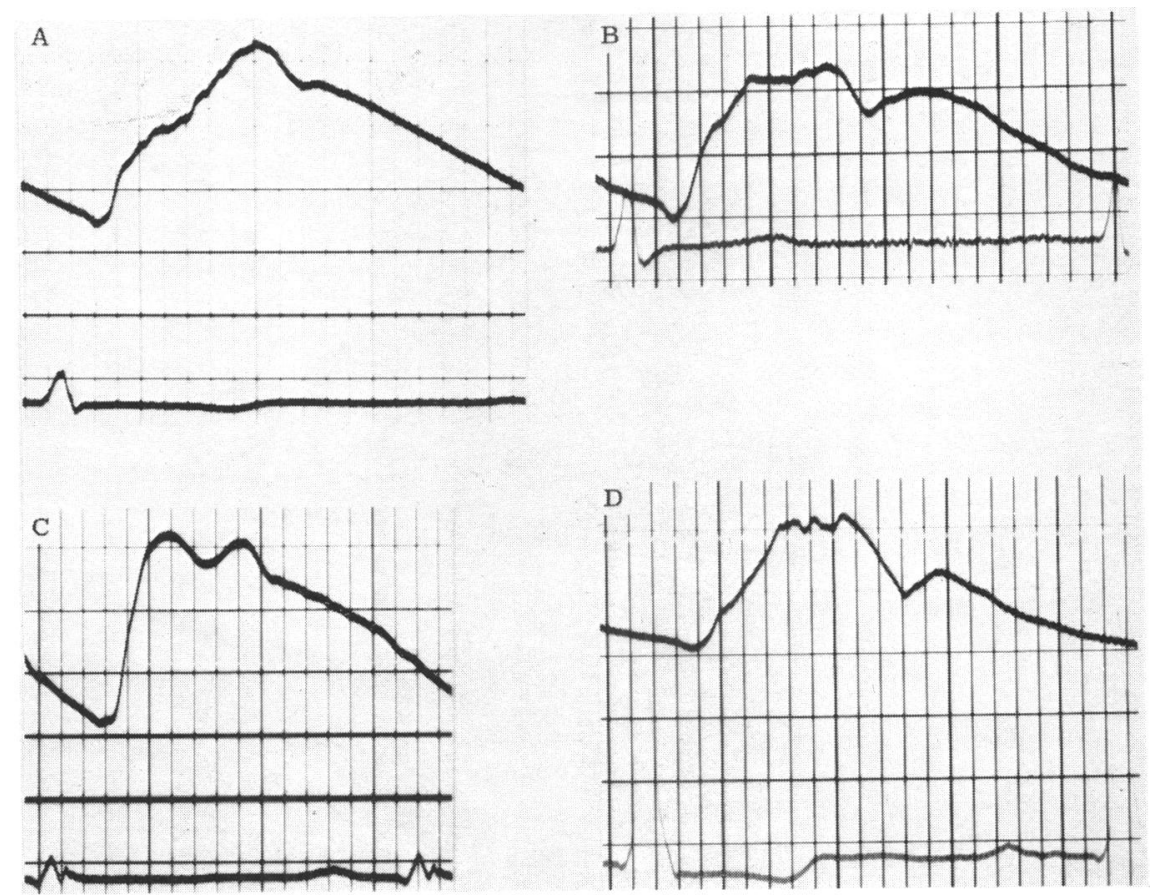

FIG. 8.-External carotid pulse in subvalvular aortic stenosis. $A$ and $B$, subvalvular membrane; $C$, muscular obstruction; and $D$, nature of obstruction unknown; patent ductus arteriosus present. The pulse changes in the patients with subvalvular membranes are indistinguishable from those of valve stenosis: A shows the typical anacrotic pattern. The pulse in the patient with subvalvular muscular obstruction is within normal limits.

not seen, particularly in the more severe cases. To achieve a high level of accuracy in diagnosis, it has proved necessary to consider three aspects of the pulse-the contour, the upstroke time, and the ejection time. Analysed in this way, aortic stenosis could be recognized in 32 out of 33 patients, the solitary failure being in a case of muscular subvalvular obstruction. External recordings are more reliable than clinical examination of the carotid pulse in the diagnosis of aortic stenosis because precise timing is possible, and they compare favourably with brachial pulse recordings. Hancock and Fleming (1960) found considerable overlap with the normal range in the brachial pulse recordings of 38 patients with aortic stenosis, and of 10 brachial pulse recordings from patients in the present series, one was normal and two did not show unequivocal change.

Carotid pulse recordings are less useful in assessing the severity and nature of an aortic valve lesion than they are in demonstrating the mere presence of obstruction. Sometimes, abnormalities are seen that point to severe stenosis or dominant regurgitation, but the graphic recording is seldom more informative than examination of the pulse by the trained finger, and it is doubtful if external carotid tracings could ever replace left heart catheterization when further investigation is needed. Possibly direct carotid pressure recordings (which are simple to perform) might prove of greater value in this respect by the addition of absolute pressure measurements. The information about the aortic valve that can be obtained from the pulse is limited by the presence of an unknown variable-the left ventricular pressure pulse.

The number of patients with subvalvular obstruction in this series is too small to permit conclusions to be drawn about the pulse, but the findings are consistent with previous reports. As has been noted by many observers, the pulse may have a sharp rise, particularly with muscular obstruc- 


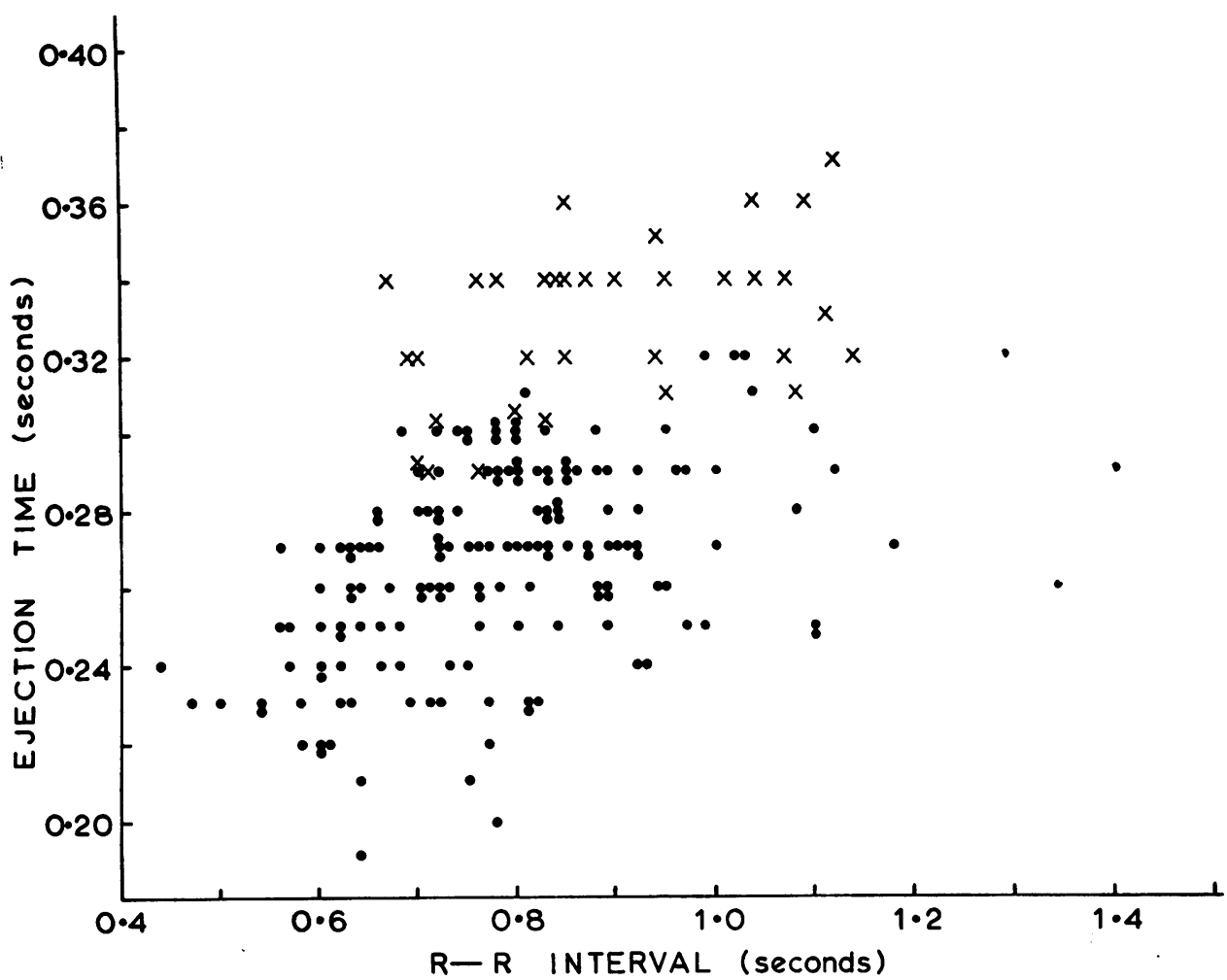

Fig. 9.-Ejection time of the external carotid pulse in 33 patients with aortic stenosis (crosses) and 164 patients with other cardiovascular abnormalities (dots) plotted against the length of preceding cycle measured from the electrocardiogram. In the absence of aortic stenosis, the upper limit of ejection time is the same as in the normal subjects (Fig. 4) and varies with the heart rate. When aortic stenosis is present, the ejection time tends to be prolonged, but there is some overlap with the normal range.

tion, but this may also occur with valve stenosis in young patients. On the other hand, typical pulse changes of valve stenosis can occur with a fixed subvalvular membrane. It thus appears that the external carotid tracing cannot exclude subvalvular obstruction in aortic stenosis, but may sometimes be of help in making the diagnosis when the obstruction is of the muscular variety.

In conclusion, the carotid pulse is of great help clinically in the diagnosis and assessment of aortic valve disease, and not the least of the uses of graphic recordings is in training the finger to appreciate the pulse contour more accurately. A slow rise to a late summit and the presence of systolic vibrations can often be recognized clinically. A small rapid initial rise, however, may be difficult to detect with the finger, but when this feature indicates that significant regurgitation accompanies aortic stenosis, it is usually augmented, and consequently more easily detected, in the brachial pulse (Robinson, 1963). Thus, since the information they provide is not infrequently complementary, the combined examination of the carotid and brachial pulses is more helpful than the examination of either alone, and is of great practical help in the evaluation of aortic valve disease.

\section{SUMMARY}

The carotid pulse has been recorded by external means in 33 patients with proved aortic stenosis (subvalvular in 4), 164 patients with other disorders of the heart and circulation, and 75 healthy 
subjects. In every patient with valvular stenosis and 3 of the 4 with subvalvular obstruction the diagnosis could be made from the pulse tracing: some correlation was found between the pulse contour and the severity of both obstruction and associated regurgitation. Criteria have been established for the recognition of aortic stenosis from the external carotid pulse tracing.

I am grateful to Dr. A. Leatham and Professor A. C. Dornhorst for much helpful advice and criticism, and to the Board of Governors of St. George's Hospital for providing a research grant.

\section{REFERENCES}

Daoud, G., Reppert, E. H., Jr., and Butterworth, J. S. (1959). Ann. intern. Med., 50, 323.

Duchosal, P. W., Ferrero, C., Leupin, A., and Urdaneta, E. (1956). Amer. Heart J., $51,861$.

Hancock, E. W., and Abelmann, W. H. (1957). Circulation, 16, 572. and Fleming, P. R. (1960). Quart. J. Med., 29, 209.

Robinson, B. (1963). Brit. Heart J., 25, 61.

Smith, J. E. (1955). Amer. Heart J., 49, 428.

- Hsu, I., Evans, J. M., and Lederer, L. G. (1959). Amer. Heart J., 58, 527.

Weissler, A. M., Peeler, R. G., and Roehll, W. H., Jr. (1961). Amer. Heart J., 62, 367. 